Revista Iberoamericana, Vol. LXXIX, Núm. 242, Enero-Marzo 2013, 95-110

\title{
LA CRÍTICA AL DISCURSO NACIONALISTA MODERNO EN LA NARRATIVA CONTEMPORÁNEA: LAS SAGAS DE INCORPORACIÓN DE "LA MOSQUITIA” EN DOS NOVELAS NICARAGÜENSES
}

\author{
POR \\ Valeria Grinberg Pla \\ Bowling Green State University
}

INTRODUCCIÓN

En febrero de 1894 tropas nicaragüenses ocuparon la ciudad de Bluefields en el Caribe de Nicaragua, declarando un estado de sitio en toda la región costeña (Hale 41; Romero Vargas 131; Vilas 88). ${ }^{1}$ Por ende, ese año la Reserva Mosquita pasó a formar parte no sólo nominal del Estado nacional nicaragüense, el cual inició una "reconquista” política, social y cultural del territorio habitado por miskitus, sumus, ramas, garífunas y creoles. Así, éstos fueron objeto de una política de ocupación y colonización interna, puesto que, como explica Germán Romero Vargas, el entonces presidente de Nicaragua, José Santos Zelaya, consideró “necesario ‘integrar’a las poblaciones del Atlántico dentro de la comunidad nacional nicaragüense de tradición hispánica” (140).

En este contexto, resulta interesante el vocabulario elegido por Zelaya para denominar la avanzada del Estado en la Reserva Mosquita, la cual fue calificada como una “reincorporación”. En efecto, dicha expresión implica la noción de que la Mosquitia había pertenecido a Nicaragua con anterioridad, por lo que en 1894 se consideró reincorporada al territorio nacional, este proceso ha sido señalado previamente por Charles Hale (38). Es por lo anterior que la épica nacionalista nicaragüense se constituye desde la narración de recuperación de un territorio perteneciente al Estado nacional-por medio de la expulsión o asimilación de los grupos étnicos que lo habitan-desarrollada en torno a la reincorporación de la Mosquitia. Este discurso se asemaja, aunque involuntariamente,

1 Philippe Bourgois hace notar que si bien la creación de la Reserva Mosquitia en 1860 colocaba al pueblo miskito bajo jurisdicción nicaragüense, al mismo tiempo le otorgaba un estatus semi-independiente que fue defendido por los miskitos cuyo rey se opuso, en 1877, a la integración de su territorio a Nicaragua aduciendo que las costumbres, religión y leyes nicaragüenses y miskitas eran incompatibles (29). Charles Hale, por su parte, explica que Zelaya fue el primer presidente que, en 1894, llevó a la práctica de manera definitiva el reclamo por la soberanía de la Mosquitia, petición que el gobierno había planteado ya desde 1860 (41). 
a un imaginario de conversión y recuperación similar al que animó la reconquista emprendida por los Reyes Católicos a fines del siglo xv en España.

En el ámbito de las ciencias sociales, las complejas y problemáticas relaciones entre los miskitus y el Estado nicaragüense han sido examinadas críticamente en las décadas recientes. Y muchas de estas investigaciones atribuyen un rol central a la intervención del Estado nicaragüense en la Mosquitia, en 1894, como hito que contribuyó a profundizar las diferencias entre la comunidad miskita y el Estado nicaragüense (Dunbar Ortiz 47; Bourgois 29; Romero Vargas 127; Hale 44-45). Es más, como apunta Charles Hale en su estudio Resistance and Contradiction. Miskitu Indians and the Nicaraguan State, 1894-1987, la reincorpación de 1894 no sólo fue un evento crucial (45), que marcaría las relaciones entre los miskitus y el Estado nicaragüense de ahí en adelante, sino que además produjo un giro en los discursos sobre dichas relaciones, ya que generó dos interpretaciones opuestas sobre la importancia de ese año:

The annexation of 1894 marked the contemporary origins of two polarized narratives of Miskitu history, though one could certainly find earlier indications of the pattern. In 1894, the discourse of Nicaraguan national sovereignity over the coast became intense and urgent, strongly encouraging Miskitu people to “join” the nation, rigidly intolerant of Miskitu thought and actions that did not conform to those plans. [...]

Accounts that take the Miskitu perspective expose the racism inherent in this nationalist hyperbole and focus on the Miskitu aspirations that the state denied at every turn. (Hale 56-57)

En relación al ámbito de la literatura nicaragüense en particular y centroamericana en general, Werner Mackenbach ha señalado que hasta los años noventa la tematización del Caribe fue poco frecuente y en los casos en los que tuvo lugar, éste "fue percibido [...] con una mirada del exterior, [que] perpetuaba la perspectiva de los conquistadores y los criollos/letrados en las ciudades del Pacífico” (Mackenbach, “Representaciones”). Así, en Nicaragua, muchas veces la literatura reprodujo, aunque no siempre conscientemente, los prejuicios étnicos que formaban parte del discurso moderno adoptado por las elites mestizas en el poder según el cual los miskitus, los creoles y otros grupos indígenas y/o afrodescendientes del Caribe eran contemplados como pueblos atrasados, por lo que su integración a la nación contribuiría a su propia civilización y desarrollo. ${ }^{2}$ Según Carlos Castro Jo, en Nicaragua, el tema racial, específicamente la actitud con respecto a los negros (asociados en el imaginario nicaragüense con la costa caribeña del país), es poco debatido y sale a la superficie "de una manera inconsciente" (21) en la vida

2 Sobre la mezcla de argumentos racistas y nacionalistas en el discurso que justificó la reincorporación de la Mosquitia en dicha fecha, véase también Vilas 89-92.

ISSN 0034-9631 (Impreso) 
cotidiana y en la literatura, lo cual hace pensar que los prejuicios modernos sobre negros e indígenas han sido ampliamente internalizados y naturalizados por grandes sectores de la población hasta nuestros días. Según Myrna Cunningham Kain, en Nicaragua,

La discriminación [...] se practica en la esfera de un Estado Nacional divido, según el desarrollo histórico de la época colonial. Primero, la Nicaragua que resultó “mestiza” en el Pacífico y la de la Costa Caribe la cual posee características culturales y lingüísticas distintas, y que fue anexada al territorio nacional pasando con ello a regirse bajo las normas de la Nicaragua “mestiza” por el gobierno de José Santos Zelaya, en 1894. Al hablar de racismo y discriminación en Nicaragua se habla de la diferencia entre “Pacífico” y “Costa Caribe”, entre un "ellos y nosotros”. (9)

Esta observación confirma la persistencia hasta nuestros días de nociones de superioridad étnica y racial propias del discurso hegemónico nacional nicaragüense, así como su anclaje histórico en la Reincorporación de la Mosquitia. Finalmente, Quince Duncan ha señalado que la negrofobia y la eurofilia han marcado gran parte de la literatura centroamericana hasta bien entrado el siglo xx (516-17).

Es en este contexto-en el cual no han abundado las obras literarias con una perspectiva crítica sobre el etnocentrismo de las políticas y los discursos nacionales en Nicaragua y Centroamérica con respecto a los afrodescendientes e indígenas que habitan la región del Caribe- en el que se inscriben las novelas Columpio al aire, de Lizandro Chávez Alfaro, y Vuelo de cuervos, de Erick Blandón, que discuto en este ensayo.

\section{COLUMPIO AL AIRE O LA DIMENSIÓN TRAUMÁTICA DE LA REINCORPORACIÓN DE LA MOSQUITIA}

Lizandro Chávez Alfaro ha sido -como lo entiende Castro Jo- uno de los contados escritores nicaragüenses "que ha explorado los temas de raza, negritud, resistencia armada y cultural contra la opresión étnica” (28-29) en el Caribe a lo largo de toda su producción literaria. No debería soprender, entonces, que la que sería su última novela, Columpio al aire, gire en torno a la “reincorporación de la Mosquitia”, evento clave de la historia de las relaciones étnicas y sociopolíticas entre los pueblos del Caribe y el Estado nacional nicaragüense. Como muchas otras ficciones históricas escritas a fines del siglo xx y principios del xxI, esta novela re-escribe un suceso histórico clave a contrapelo del discurso de la historiografía nacional oficial, la cual (salvo contadas excepciones) se ha cartacterizado por asumir de manera acrítica las aspiraciones nacionalistas del Estado nicaragüense con respecto a la Mosquitia. ${ }^{3}$

3 Sobre las características de las nuevas novelas históricas en Centroamérica, véase Grinberg Pla 19-39. Con respecto a Columpio al aire como novela histórica, véase Aguirre 83 y Rodríguez.

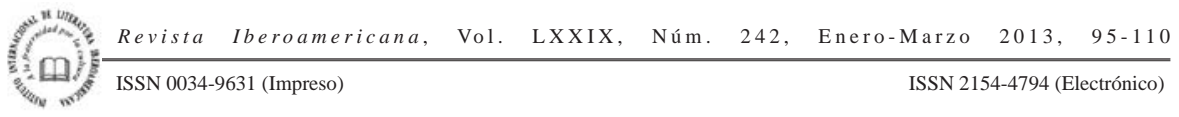


Así, esta novela narra la imposición de la autoridad del Estado nicaragüense a los habitantes de Bluefields a fines del siglo xIx, al tiempo que describe la incapacidad de los representantes del gobierno nacional, el general Migloria y el teniente Sanarrusia, para entender el punto de vista de la gente del lugar. Uno de los hechos a través de los cuales el narrador omnisciente retrata la soberbia del Estado en su desdén por las tradiciones miskitas es la decisión de Migloria de trasladar el cementerio a un nuevo lugar, obligando a los pobladores a desenterrar a sus muertos para volver a sepultarlos en el nuevo panteón laico. No por casualidad, el general arenga a los lugareños sobre los beneficios de la política del Estado nicaragüense en el cementerio mismo, haciendo demostración pública de su poder en el lugar mismo de la disputa. Simbólicamente, la orden de desplazar las tumbas implica un reordenamiento del espacio urbano que perturba la relación de la comunidad con su/s (ante)pasado(s) por lo que el cementerio funciona como sinécdoque de Bluefields o incluso de toda la Mosquitia. Es decir que en Columpio al aire el Estado se arroga el derecho de determinar el lugar del pasado británico y de la presencia de miskitus y creoles (representados ambos por los antepasados enterrados en el viejo cementerio) en la nueva configuración urbana, reflejo de la "reconquista" nacional del espacio. Así, el traslado del cementerio expresa la potestad del Estado sobre los cuerpos, vivos y muertos, que deben ser reordenados, es decir, disciplinados para poder ser reintegrados a la nación.

Dos personajes son conscientes de las implicaciones de dicho traslado, si bien sus reacciones son distintas: Safá Kubrik y Viola Hendy; ambos, como se verá más adelante, son centrales en la novela. El primero es un comerciante, probablemente de origen europeo, con un rol tan prominente como ambiguo en la comunidad, ${ }^{4}$ el cual vive en Bluefields desde antes de 1894. Su condena respecto al traslado forzado del cementerio se reduce al siguiente comentario: "No hacía falta meterles el hocico del poder entre sus huesos muertos. [...] Es demasiado. A los vencidos, aniquilarlos o dejarlos vivir con sus cosas de costumbre [...]” (Chávez Alfaro 18). El cinismo distanciado de esta frase, adaptación de Kubrik de las ideas de Maquiavelo, deja entrever que él no es miembro de la comunidad. Ni en este contexto ni en ningún otro se especifica el origen de Kubrik de modo que la ambigüedad es extendida a su nacionalidad y su etnia. Carlos Castro Jo ya ha llamado la atención sobre el hecho de que los personajes de Chávez Alfaro no son reducidos a su color o etnia (29). Así, ni en el caso de Kubrik, ni en el de Viola Hendy se

${ }^{4}$ La ambigüedad de su posición se debe a que los miembros de la comunidad sospechan que los ha traicionado. Como los conspiradores no han tratado directamente con él, no saben exactamente qué ha ocurrido y si Kubrik es culpable (Chávez Alfaro 45-46, 48). Lo interesante es que tampoco el lector lo sabe a ciencia cierta, ya que el texto no devela esta incógnita. Así, para los lectores y la comunidad miskita y creole por igual, Kubrik es un personaje tan hermético como la parábola con la que intenta probar su inocencia (51-53).

ISSN 0034-9631 (Impreso) 
hace referencia al color de la piel. Esta indeterminación étnica/racial es válida para casi todos los personajes costeños en la novela y puede responder tanto a una conciencia de los numerosos mestizajes entre creoles y miskitus (Gordon 33-44) como a un rechazo consciente de la racialización por parte del autor.

Viola Hendy, por su parte, hermana del rey miskitu depuesto, cuestionará abiertamente a Migloria en repetidas oportunidades, en un reclamo indignado en respuesta a la afrenta que significa para ella la profanación de las tumbas de sus muertos. En el primero de esta serie de cuestionamientos, presa de la indignación, Viola interpela a Migloria en público, interrumpiéndolo en su discurso, en una escena que coloca la diglosia en el centro del conflicto de la ocupación:

Los oropeles de la casaca pretenciosa de Migloria, convertían en destellos los movimientos de su torso pechudo. Arengaba a sus conquistados...

La voz teatral de Boggs era una pobre adherencia de los engolados párrafos del generalintendente. Contra la dicha recordada de haber representado airosos personajes de teatro (hijos de autores enormes: B. Jonson, Ch. Marlowe, y W. Shakespeare) se le venía encima la desdicha de estar representando en pleno día a un idiota que profanaba una tumba en dos idiomas.

En su doble ansia de serle útil a Migloria y de disolverse ante los oyentes, reducía largas tiradas a pocas frases. Cuando Migloria se esmeró en decir mi gobierno y las tendencias de su política sólo se encaminan a dar a este honrado y laborioso pueblo los valiosísimos privilegios de la paz y la libertad, los sagrados dones de la dignidad y el progreso, el intérprete se limitó a transmitir: "dice que con ellos viene el progreso y la paz".

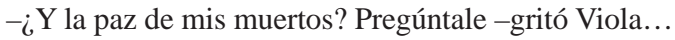

-Pregúntale si es progreso alambrar tumbas como si fueran vacas. (Chávez Alfaro 20-21)

La necesidad de un intérprete (el teniente solamente habla español, mientras los bluefieleños hablan miskitu y/o inglés creole) como mediador entre ambas partes que alude a los varios componentes de la distancia cultural que separa a los representantes del Pacífico de los habitantes del Caribe. En Columpio al aire se sugiere que esta diglosia no se limita al ámbito lingüístico, sino que se trata de una diglosia en sentido extenso que incluye otros aspectos clave de la vida cultural, como los ritos funerarios, las fiestas, la religión, la música, la literatura y la educación. Así, estas áreas constituyen lugares de imposición de la lengua/cultura dominante, es decir que se transforman en campos de batalla en donde los representantes del Estado imponen y los "conquistados" resisten. El parlamento de Migloria deja entrever las nociones de superioridad cultural y étnica (que justifican la misión civilizadora del Estado) implícitas en su ideología, las cuales se traducen en el privilegio sociopolítico de los recién llegados del Pacífico y en el desdén frente a las prácticas culturales y religiosas de los miskitus y creoles. Al mismo tiempo, el pasaje arriba citado no sólo presenta el cuestionamiento de Viola Hendy de la

\footnotetext{
Revista Iberoamericana, Vol. LXXIX, Núm. 242,
ISSN 0034-9631 (Impreso)
} 
concepción de progreso del Estado nicaragüense, además, por medio de la focalización del narrador en Boggs, el intérprete, se permite entrever el bagaje cultural británico de los bluefieleños y su competencia ligüística (el bilingüismo), lo que también pone en cuestión su supuesto atraso.

Por eso, según la novela de Chávez Alfaro, la ocupación cívico-militar de Bluefields a partir de 1894 generó una situación de diglosia en sentido extenso, en la cual los privilegios sociopolíticos concedidos a los representantes del Estado nicaragüense respondían a una equiparación del progreso de toda la nación con los valores culturales de la región "mestiza” del Pacífico, por lo que estos últimos debían ser impuestos a los miskitus y creoles de la Costa Atlántica. En consecuencia, tiene lugar una "reconquista" para lograr que la realidad social de la Mosquitia coincida con la comunidad homogénea imaginada por el Estado nacional: se traslada el cementerio, se prohíbe la enseñanza en otro idioma que no sea el español y se organizan las fiestas católicas de San Jerónimo, entre otras muchas acciones.

La empatía del narrador omnisciente de Columpio al aire con los miskitus es más que evidente a lo largo de toda la novela y no sólo en la extensa cita discutida arriba. Por eso resulta apropiada la observación de Werner Mackenbach, quien llama la atención sobre el cambio de perspectiva en la narración que se produce en este texto por primera vez en la narrativa nicaragüense: el pasaje de una mirada exterior a una interior ("Representaciones”).

Como vimos, la convivencia de los representantes del Estado y los pueblos caribeños no es harmónica. Es más, la diglosia, siempre entendida en sentido amplio, acentúa el carácter traumático de la reincorporación porque implica una actualización cotidiana de los privilegios sociopolíticos de unos frente a la impotencia de otros. En otras palabras, Columpio al aire inscribe la reincorporación de la Mosquitia como trauma para los miskitus y creoles porque pone en escena un país dividido diglósicamente en dos regiones, la región del Pacífico se instala literalmente en la región del Caribe. Los representantes del Estado in situ, Migloria y Sanarrusia, inscriben la imposición moderna y nacional en los cuerpos/el espacio del Caribe por medio de su disciplinamiento y reordenación.

El hecho de que la novela de Chávez Alfaro retrate críticamente la reincorporación de la Mosquitia en particular, y la relación del Estado nicaragüense con los pueblos del Caribenicaragüense en general, ya ha sido suficientemente señalado por la crítica (Addis, Aguirre, Bachmann, Mackenbach, Rodríguez). Por eso, lo que me interesa resaltar es que, además, dicho autor interpreta la diglosia producto de la reincorporación como trauma.

La condición traumática, es decir no resuelta, de la asimilación forzada al Estadonación es evidenciada por la coexistencia diglósica de dos realidades en un mismo espacio, como por ejemplo la calle central de Bluefields, centro político, social y cultural del territorio en disputa:

ISSN 0034-9631 (Impreso) 


\begin{abstract}
Aunque ocupando el mismo espacio público, mirones y mirados permanecían en sitios separados por la imaginación. Estaban en tiempos distintos. Mientras unos iban caminando por lo que siempre sería para ellos la Calle del Rey, los otros estaban plantados al borde de lo que hacía dos años, desde agosto de 1894, habían decretado llamar la Calle del Comercio. En cualquiera de sus posiciones, móviles o inmóviles, intruso era el otro, la otra, los otros. (Chávez Alfaro 2)
\end{abstract}

Dos cuestiones saltan a la vista en este pasaje: por un lado, la existencia superpuesta de dos espacios en uno, por lo que se puede afirmar que el autor está proponiendo entender Bluefields como un espacio heterotópico. Tal y como explica Michel Foucault, la heterotopía tiene el poder de yuxtaponer en un mismo lugar diferentes espacios incompatibles entre sí (354). Al igual que la diglosia, la heterotopía es consecuencia directa de la reincorporación de la Mosquitia y síntoma del trauma que provoca porque remite a la inviabilidad del Reino Miskitu/la Calle del Rey debido a la imposición del Estado nicaragüense/la Calle del Comercio.

Por otro lado, el pasaje citado sugiere que los costeños, para preservarse a sí mismos en dichas circunstancias, reafirman las coordenadas tradicionales de su ciudad, lo que a su vez los ancla en el pasado. Este volcarse sobre el pasado es, sin duda, otro síntoma del trauma. Parafraseando a Henri Lefebvre (145), me aventuro a sugerir que los miskitus y creoles de Columpio al aire, en tanto habitantes de la ciudad, la conciben como un espacio vivido, concreto y subjetivo, es decir, ligado afectivamente a sus experiencias pasadas, a contracorriente del espacio abstracto representado en los planes urbanísticos modernos de Migloria, punta de lanza de la integración de la capital de la Mosquitia a la nación. Por eso, aquéllos siguen transitando por la Calle del Rey, bajo el control de la mirada de quienes buscan imponer el nuevo orden político y social.

Porúltimo, la dimensión traumática de la reincorporación para los miskitus y creoles es representada ritualmente por medio del sacrificio de Viola Hendy. En efecto, como acto de resistencia a la ocupación el ya mencionado Safá Kubrik, junto al reverendo de la Iglesia Morava, planea presentar en público, por primera vez en Bluefields, El Mesías, de Händel. Este proyecto es un contraataque frente a la avanzada hispanista y católica del gobierno de Nicaragua: contrapartida de las fiestas de San Jerónimo organizadas por Migloria. ${ }^{5}$ Además, este acto afirma el derecho de la comunidad de Bluefields al legado cultural británico, no como imitación de las prácticas culturales del Reino Unido, sino en una apropiación que necesariamente implica cambios, porque, como explica el narrador, Ocelin, la cantante que ha suplantado (a los ojos de la comunidad) a la misteriosamente desaparecida Viola (quien había sido seleccionada como solista en primer lugar):

5 Sobre la función de El Mesías en la novela, véase Bachmann.

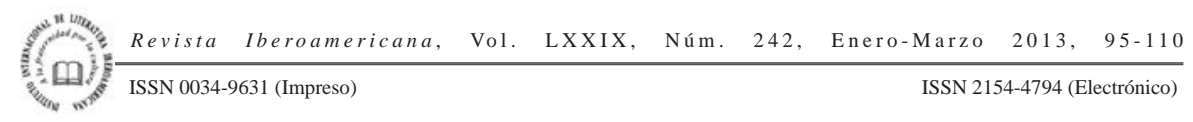


[...] hacía lo suyo en Bluefields, con el íntimo deseo de parecerse en todo lo posible a la volatilizada Viola Hendy, y no a cualquier voz célebre de Westminster. Se trataba de El Mesías elevado como catedral sonora en las costas de la bahía de Bluefields, y no de reproducir un facsímil de cualquier otra ejecución, como pretende la obcecación racista. (Chávez Alfaro 196)

En efecto, aunque Viola ha sido elegida como intérprete principal no podrá participar de cuerpo presente el día de la ejecución pública, ya que será sacrificada por Kubrik en una violenta operación en la cual la asesina por medio de la mutilación de su "fatal triángulo púbico” (Chávez Alfaro 193). La brutalidad del ritual ${ }^{6}$ parece tener que ver no tanto con "todas las injurias que de mujer [Kubrik] había recibido en varios idiomas" (Chávez Alfaro 191) ni con una ambigua condena de la homosexualidad femenina y de las mujeres solteras e independientes que atraviesa toda la novela $(10,12,16,90$, 178-79, 180, 192-93, 196), sino con un deseo de que la "sagrada ceremonia de los triángulos” (194) perpetúe la presencia de Viola Hendy (sumando por este medio otra coordenada a la demarcación miskita del espacio heterotópico de Bluefields), como (porta)voz de la diferencia étnica y cultural de los miskitus. Así, el día del concierto, y ante la sorpresa del público: "cada vez fue más clara la voz de Viola Hendy, insuflada desde cualquier ángulo del círculo; el nacimiento de Venus manifestado a través de la garganta de Ocelin Willis; más clara, hasta que nadie dudó de que la Diosa del Tiempo volvía [...]" (Chávez Alfaro 196). En mi opinión, es importante tener en cuenta que, además, el sacrificio de Viola y la posterior reaparición de su voz colocan un cuerpo de mujer en el centro de la disputa por el derecho a la identidad étnica/cultural/nacional, en una larga tradición en la cual los cuerpos femeninos han servido como representaciones alegóricas de la nación. Así, Viola Hendy, la mujer que no ha conocido varón, simboliza la nación miskita en resistencia a la penetración cultural del Estado nicaragüense; pero también es la víctima concreta cuyo sacrificio permite la supervivencia cultural de su comunidad: de ahí que su muerte aluda a la condición traumática de la ocupación.

La desaparición física de Viola, su muerte, no implica su ausencia o su olvido, del mismo modo que la reincorporación de la Mosquitia y su pérdida de autonomía no implica el fin de una identidad nacional miskita. De modo que, nuevamente, Columpio al aire invita a leer la situación del Caribe nicaragüense como una heterotopía.

Finalmente, podría pensarse que el trauma de la ocupación no sólo regresa a modo de símbolo en la voz de la desaparecida Viola/Reserva Mosquitia, sino que ha tenido un retorno histórico en la política del gobierno sandinista en la Costa Atlántica, una política que, al decir de Carlos Vilas, "fue enfocada por el FSLN como una dimensión regional

6 "Roncadores, bagres y mutruces hicieron su fiesta de carne de mujer cortada en precisos triángulos y arrojados al agua por una escotilla del piso bajo. Una mancha roja fue disolviéndose en el agua agitada; disolviéndose hacia los confines de la noche. Carne de una Diosa del Tiempo” (Chávez Alfaro 194).

Revista Iberoamericana, Vol. LXXIX, Núm. 242, Enero-Marzo 2013, $95-110$
ISSN 2154-4794 (Electrónico) 
de la problemática de la dependencia y el atraso, pero sin incorporar de manera orgánica a las variables estructurales los elementos diferenciales étnicos de la región” (193-94).

Por cierto, esta alusión indirecta al presente que tiene lugar en Columpio al aire es una de las características centrales de las novelas históricas de las últimas décadas y responde, a mi entender, a una reescritura del pasado "como una forma de entender la situación actual y en vistas hacia el futuro” (Grinberg Pla 37), en un gesto que sostiene la contemporaneidad de la historia. Al respecto, Mary K. Addis ya ha señalado que:

[...] la novela [de Chávez Alfaro] parece aludir, de modo indirecto pero inequívoco, a la época sandinista y la política sandinista en cuanto a la región caribeña durante los años de guerra de los ochenta: la actitud autoritaria del gobierno del Pacífico, el desdén por la cultura caribeña, la resistencia y rebelión por parte de los indígenas de la Mosquitia ante las medidas impuestas por el gobierno en Managua.

Si Columpio al aire alude tan sólo indirectamente a las políticas sandinistas en el Caribe nicaragüense, la novela de Blandón, Vuelo de cuervos, en un gesto abiertamente político (Delgado Aburto 82), tematiza específicamente "[u]no de los episodios más traumáticos de la compleja relación de la revolución con las poblaciones indígenas costeñas” (Vilas 290): el traslado de las comunidades miskitas del Río Wanki/Coco, en la frontera con Honduras, a un asentamiento creado ex profeso en un área alejada de la zona de guerra que se llamará Tasba Pri.

VUELO DE CUERVOS O LA MASCARADA DEL MULTICULTURALISMO SANDINISTA

De acuerdo con el Estatuto de Autonomía de las Comunidades de la Costa y con la Constitución de Nicaragua promulgados por el gobierno sandinista, éste es un país multiétnico, y por tanto el Estado reconoce el derecho de las comunidades del Atlántico a preservar su identidad cultural, es decir, a desarrollar sus lenguas, religiones y culturas en igualdad de derecho con los habitantes del Pacífico (Freeland 111-15).

Aunque el mundo novelado por Erick Blandón es anterior a dicho Estatuto, su novela critica precisamente la política multiculturalista del sandinismo que se expresa en el mismo. Así, Vuelo de cuervos se propone desenmascarar lo que considera el carácter formal de la política multiculturalista revolucionaria, llamando la atención-por un ladosu paternalismo (ya que siempre serán los altos mandos sandinistas los que decidan de hecho por y para las comunidades del Caribe) y -por el otro- sugiriendo que la política oficial es etnocéntrica porque actualiza nociones de superioridad cultural arraigadas de manera más o menos consciente de la elite en el poder.

Una de las escenas en las que Vuelo de cuervos retrata con claridad la actitud paternalista y etnocéntrica sandinista con respecto al pueblo miskitu consiste en el diálogo entre un mayor del ejército sandinista y su ayudante, Pancho, en el que el primero le

\footnotetext{
Revista Iberoamericana, Vol. LXXIX, Núm. 242,
ISSN 0034-9631 (Impreso)
} 
pide al segundo que averigüe "qué diablos les pasa a esas nativas, que no han parado de gritar aluy, aluy, aluy" (Blandón 52) porque ya lo tienen "agüevado" (52). ${ }^{7}$ Nótese que el interés del mayor no tiene que ver con una preocupación por lo que pueda estar pasándoles a las "nativas", sino simplemente le molesta tener que escucharlas. Cuando Pancho le cuenta que las miskitas empezaron a llorar porque los soldados están tirando abajo los cocoteros a fuerza de machete, su superior no encuentra "convincente" semejante explicación. En otras palabras, no sólo le es imposible comprender otros parámetros de relación con la naturaleza que no sean los propios, sino que además considera ridículas las creencias miskitas, por lo que su desdén será abierto: "Estas indias sí que son... tanto lloro por un tronco. Yo no le hallo" (53). El hecho de que el oficial del ejército sandinista no quiera escuchar el llanto/las voces de las mujeres miskitas sin duda alude, desde la visión de las prácticas sandinistas de Vuelo de cuervos, a un desinterés mucho más amplio del gobierno con respecto a las necesidades o derechos de los miskitus.

De modo característico para el estilo de esta novela, en la que las voces narrativas no siempre siguen el orden cronológico o bien relatan un mismo episodio más de una vez, pero con un enfoque diferente, unas páginas más adelante se relata una discusión entre dos brigadistas, Inés del Monte y Homero, por un lado, y el capitán cuyo nombre simbólico es Malpartida, por el otro, el cual está a cargo del traslado de los miskitus al nuevo asentamiento. El motivo de la disputa es que estos brigadistas le exigen a dicho capitán que impida a los soldados seguir derribando cocoteros. Mientras los primeros quieren respetar el entorno y las creencias de los miskitus, al segundo lo único que le importa es que su tropa pueda alimentarse con rapidez, por lo que hace oídos sordos a sus demandas. La dolida respuesta de Homero equipara el etnocentrismo desde el cual los sandinistas usufructúan los recursos naturales en su provecho (desoyendo las demandas de los indígenas y sus portavoces) con la postura de superioridad étnica y cultural con la cual los españoles impusieron sus costumbres durante la conquista: "A este paso voy a creer que [los miskitus] nos dicen españoles no porque hablamos castellano sino porque actuamos igual que los conquistadores, arrasándolo todo, quemándolo todo y destruyendo las creencias de los nativos” (Blandón 59). En este contexto, me parece significativo que la crítica de Vuelo de cuervos a la política/ideología sandinista en la Costa Atlántica coincida con las observaciones de investigadores como Charles Hale, quien sostiene que todavía existen muchas cuestiones sin resolver en la visión sandinista de una Nicaragua verdaderamente igualitaria y multiétnica (36). Es más, según este antropólogo,

\footnotetext{
7 Otro claro ejemplo de la "retórica ilustrada" (Delgado 59) del discurso revolucionario así como de su "marca colonial” (Delgado 86) es el discurso del delegado del gobierno y máxima autoridad en la costa, Narciso Pavón (Blandón 26-29).

$\begin{array}{lllll}\text { Revista Iberoamericana, Vol. LXXIX, Núm. 242, Enero-Marzo 2013, } & 95-110 \\ \text { ISSN 0034-9631 (Impreso) }\end{array}$
} 
Sandinista leaders proceeded according to premises inherited from the past century of unequal relations between Miskitu people and the state and adapted them to the framework of Mestizo revolutionary nationalism. They tended to exclude Miskitu people from the category of "historical subjects" and to constitute a national identity nourished by an Indian past but headed resolutely toward a unified Mestizo future. (164-65)

Uno de los aspectos distintivos de Vuelo de Cuervos son los reclamos al "nacionalismo revolucionario mestizo" por la toma de decisiones desde arriba, sin tener en cuenta el punto de vista miskitu; por las arbitrariedades y maltratos cometidos durante el traslado de las comunidades del Río Coco, arriba mencionados; por el enamoramiento de la cúpula sandinista (llamada burlescamente Coro de Ángeles) con el poder y su consecuente corrupción; y por el modo en que la dirigencia sandinista se apropia del capital cultural simbólico de los miskitus en un acto de rapiña, que convierte a los “ángeles" en "cuervos”. En palabras de Leonel Delgado, la novela de Blandón descubre "la tecnología del poder [sandinista] que pretende consumir las identidades" (83). En definitiva, la novela pone en escena las contradicciones del discurso nacionalista sandinista del Pacífico. En relación a lo anterior, Werner Mackenbach puntualiza que en Vuelo de cuervos los miskitus son meros objetos del discurso del Pacífico, el cual es visto, por cierto, con una mirada crítica (Unbewohnte Utopie 397). Pero tal vez esto se deba a que la novela gira precisamente en torno a la incapacidad de los líderes sandinistas de ver a los miskitus como sujetos de la historia.

Ahora bien, Vuelo de cuervos, por medio de la carnavalización de la política sandinista en la costa, hace un cuestionamiento del discurso revolucionario nacional y su proyecto liberador/modernizador de los miskitus, que no es exclusivo de la literatura, pero que ésta lleva a cabo de manera particular. Como resalta Arturo Arias, la narrativa centroamericana de las últimas décadas experimenta una transformación en los modos de narrar, convirtiéndose en un "campo de juego de pirotecnia e intercambio verbal para visualizar nuevos modelos de realidad, espacio y tiempo" (22; mi traducción). La puesta en escena de diferentes voces de la que habla Arias es una de las características centrales de la novela de Blandón, dado que los eventos son narrados desde diversas perspectivas: la del intelectual Laborío, cuya narración en primera persona abre y cierra la novela; una voz omnisciente en tercera persona; y la reproducción del discurso directo de numerosos miembros de la brigada sandinista en la costa, de los comandantes sandinistas y en menor medida de algunos miskitus, así como desde varios intertextos como cartas, discursos y canciones reproducidos en diversos idiomas.

Las diferentes voces del texto apuntan a exponer las contradicciones e hipocresías atribuidas a los líderes sandinistas en el poder al tiempo que hacen visible el maltrato que reciben los miskitus. Sin embargo, y como ya han señalado Werner Mackenbach y Leonel Delgado, las voces de éstos o bien son anónimas o bien son mediatizadas por los mestizos del Pacífico. Este es el caso de la miskita Matemática/Siboney quien “informa

\footnotetext{
Revista Iberoamericana, Vol. LXXIX, Núm. 242,
ISSN 0034-9631 (Impreso)
} 
a Laborío sobre varios aspectos de la cultura miskita que luego él refuncionaliza en su relato denunciatorio" (Delgado Aburto 93). Asimismo, los brigadistas críticos, Homero e Inés del Monte, asumen, como vimos, el rol de portavoces de las quejas de los miskitus. De modo que en Vuelo de Cuervos los miskitus cumplen un papel de informantes nativos de los intelectuales del Pacífico. ${ }^{8}$

En efecto, otro de los temas centrales de la novela es la misión del protagonista, Laborío, a quien los altos mandos sandinistas le han encargado escribir una memoria de los sucesos importantes que vivirá en la Costa Atlántica como parte de la brigada destinada allevar a cabo los desplazamientos de los miskitus. Sin embargo, el protagonistanarrador se entera, ya bien avanzada la trama, de que la comandancia en realidad nunca tuvo la menor intención de publicar su memoria de los eventos. Es más, la nota que él mismo debe llevar consigo y entregar al jefe militar de la costa (la cual según lo que le habían hecho creer contenía un secreto militar) revela el absoluto desdén de la dirigencia por su trabajo intelectual. Como la nota en cuestión termina por circular libremente, Laborío se convierte en un hazmerreír público. Ahora bien, en lugar de desistir de su proyecto de escribir una memoria y de ocultar su escarnio, en el último capítulo de la novela el protagonista-narrador reproduce el texto de la oprobiosa nota, exhibiendo frente al lector la zancadilla que le tendió la dirigencia sandinista y reproduciendo, en cierto sentido, la autoironía que recuerda la perspectiva narrativa del pícaro (no es por casualidad que en este contexto el narrador cite El Periquillo Sarniento, de Joaquín Fernández de Lizardi). Así, reflexionando sobre las posibles reacciones de los lectores, Laborío devela que la totalidad de la novela no es otra cosa que la memoria indeseada de la actuación de los sandinistas en el Caribe. Blandón/Laborío al igual que Lizardi/el Periquillo Sarniento escribe su sátira social para “enseñanza y deleite” (Blandón 272), porque, como dice el Pensador,

Un libro de estos lo manosea con gusto un niño travieso, el joven disipado [...] y aún el pícaro y tuno descarado. Cuando estos individuos lo leen lo menos en que piensan es en sacar fruto de su lectura. Lo abren por curiosidad y lo leen con gusto, creyendo que solo van á divertirse con los dichos y cuentecillos, y que este fue el único objeto que se propuso su autor al escribirlo, pero cuando menos piensan ya han leído una porción de máximas morales, que jamás hubieran leído en un estilo serio y sentencioso. (Lizardi 237)

Para desenmascarar el carácter meramente formal del respeto sandinista por la diferencia cultural de los miskitus, vengándose de paso por cómo lo han tratado, Laborío narrará el modo inadecuado en el que el gobierno se apropia del festival cultural Kupia Kumi, cuya finalidad era exhibir y celebrar la "nación multiétnica, plurilingüística" (Blandón

8 Para un análisis crítico del rol del letrado en la revolución sandinista y en su relación de mediador entre los subalternos y el Estado, según Vuelo de Cuervos, véase DelgadoAburto 82-84.

ISSN 0034-9631 (Impreso) 
198). Dicho encuentro multicultural no solamente busca encubrir la violencia de los desplazamientos forzados, sino que también muestra la avidez del poder por vender las identidades culturales como espectáculo. Al respecto, Leonel Delgado acota que:

[... ] el “espectáculo estatal” supone la cancelación de la subjetividad y la anulación de un verdadero "encuentro cultural”. La venganza/escritura del intelectual burlado por el poder es una solución intermedia y provisional que testimonia las distancias insalvables o sospecha qué otras formas culturales lograrían ese encuentro hipotético. (84)

No obstante la provisionalidad del remedio implicado en la sátira del sandinismo que lleva a cabo la novela de Blandón y del lugar mediatizado que ocupa la voz miskita en la misma, hay un momento en el cual los miskitus resisten que su identidad sea consumida totalmente por el poder. Disfrazados de zopilotes, los miskitus se avienen a bailar para regocijo del Coro de Ángeles y los turistas de la revolución. Sin embargo, el final planeado y esperado por los líderes mestizos del Pacífico, en el cual luego de la muerte de los zopilotes -símbolo del "imperialismo representado por el pájaro negro" (Blandón 262)-, el espectáculo debe culminar con una suelta de palomas blancas-símbolo expreso de la paz y, ¿por qué no también?, del reino del Coro de Ángeles-, fracasa, ya que los brigadistas no logran hacerlas volar. En cambio, para sorpresa de todos los presentes, una música que viene de la costa sustituye a El Zopilote, por lo que todos los espectadores van a la playa a ver de qué se trata. Allí se encuentran tan sólo con su “zopilotera muerta y un letrero clavado a una estaca en la arena: Cotón Azul Volbió” (Blandón 267; énfasis en el original). En otras palabras, en la visión de los miskitus para la Costa Atlántica en la nueva Nicaragua revolucionaria, los vencedores o salvadores no son las palomas "angélicas” que remiten a la dirigencia sandinista, sino el héroe mítico miskitu. Por eso me inclino a pensar que Vuelo de Cuervos sugiere que en medio de la mascarada que los sandinistas convierten al Kupia Kumi y en medio de la acomodación de los miskitus, éstos todavía son capaces de gestos de resistencia cultural.

La perspectiva crítica del paternalismo del gobierno frente al pueblo miskitu que sostiene la novela adolece, sin embargo, de una mirada exotizante sobre el Caribe nicaragüense que codifica dicha realidad desde una perspectiva masculina heterosexual. En efecto, Laborío accede al conocimiento de la realidad miskita gracias a sus relaciones sexuales con Matemática/Siboney, y, no por casualidad, tiene una epifanía sinestética en la que el pedazo de coco que ella le da de comer y la visión de sus pechos desnudos significan los ríos de leche y miel que promete la revolución sandinista (Blandón 24), de modo que la utopía de la felicidad en este mundo se encuentra directamente ligada al goce sexual de la mujer/la comida de la costa. El narrador omnisciente también es seducido por la geografía del Caribe y hace una loa de los pinos caribeños en clave sexual:

\footnotetext{
Revista Iberoamericana, Vol. LXXIX, Núm. 242,
ISSN 0034-9631 (Impreso)
} 
El elevado pino caribe mueve su cintura y parece una negra con la falda de agujas recogida en lo alto. Mueve las caderas de atrás para adelante y de adelante para atrás, mientras entre sus piernas un negro se contonea boca arriba, porque oye el Palo de Mayo que el viento le toca. ¡Qué pinos del norte ni qué pinos de Italia! (Blandón 36)

Es decir que la sexualización de la realidad caribeña es un componente innegable de la perspectiva de la novela. En este contexto no puedo menos que notar el paralelismo con Columpio al aire, en donde una mujer miskita cuyo cuerpo/voz simboliza toda la nación es sacrificada: las dos novelas tienen una mirada de género claramente heterosexual y masculina. Si en ambos textos tiene lugar una reflexión crítica sobre el etnocentrismo del discurso nacional moderno, no puede afirmarse lo mismo con respecto al falocentrismo que, de igual manera, forma parte de dicho discurso.

\section{CONSIDERACIONES FINALES}

Escritas a finales de los noventa, ambas novelas comparten una mirada crítica frente a los discursos y las políticas nacionalistas modernas del Estado nicaragüense que afirmaron su potestad sobre los miskitus y otros pueblos del Caribe. Mientras Lizandro Chávez Alfaro alude tan sólo indirectamente a la política sandinista en los ochenta, centrando su novela en la reincorporación de la Mosquita en 1894, Erick Blandón lleva a cabo una crítica explícita de la misma. No obstante esta diferencia, los dos llaman la atención sobre el colonialismo interno que ha tenido lugar en Nicaragua en distintas épocas como ejemplo cabal de la imposición de la modernidad en América Latina en donde, como explica Kemy Oyarzun, "hablar de ‘una nación’ implica la amputación de las otras 'naciones' que, a pesar de la conquista, no han sido incorporadas por los estados mal llamados modernos" (citado por Delgado 59). Así, mientras Columpio al aire inscribe en la literatura la dimensión traumática de la (re)incorporación de la Mosquitia ordenada por el general Zelaya a fines del siglo xIx, Vuelo de Cuervos sugiere que el discurso revolucionario de la "nación multiétnica y plurilingüística" esconde los mismos prejuicios etnocéntricos modernos que caracterizaron el discurso liberal un siglo antes. Así, el discurso del sandinista Chico Pavón en Vuelo de cuervos parece un eco de la arenga del liberal Migloria en Columpio al aire, pues ambos comparten un sentimiento de superioridad cultural y étnica que justifica la misión civilizadora del Estado.

La diglosia (en sentido extenso) que caracteriza a Bluefields, según Chávez Alfaro, no es resuelta por medio del encuentro cultural, Kupia Kumi, organizado por los sandinistas en los ochenta. Por el contrario, la potencialidad de verdadero diálogo que ofrecería dicho encuentro es desvirtuada por su transformación en espectáculo por parte de la cúpula sandinista.

La resistencia cultural (la representación de El Mesías y el final inesperado en la danza de los zopilotes miskitus) es acotada pues exige, en el primer caso, la muerte de

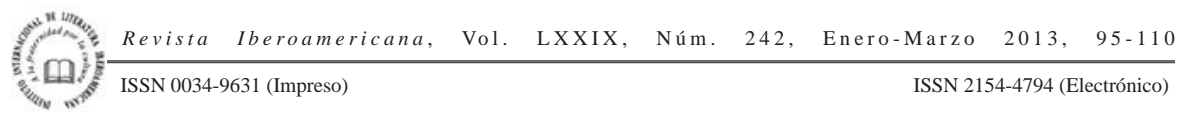


Viola Hendy y, en el segundo, porque está mediatizada por la narración del intelectual mestizo. De cualquier manera, la voz miskita sólo circula de manera interpósita, en la voz o en la escritura de otros.

Sin embargo, estas novelas sobre la relación de Nicaragua con el Caribe, así como las deAnacristina Rossi sobre Costa Rica (Limón Blues y Limón Reggae), Rafael Ruiloba sobre Panamá (Manosanta) y Julio Escoto sobre Honduras (Rey del Albor, Madrugada), utilizan el espacio de la ficción como lugar en el cual se repiensan críticamente las políticas de los Estados nacionales. Al mismo tiempo, ponen a circular en Centroamérica, y más allá también -pero con las limitaciones que implica su reproducción mediatizada-, las voces de las otras naciones amputadas.

BiBLIOGRAFÍA

Addis, Mary K. "In Memoriam: Lizando Chávez Alfaro (Bluefields 1929 - Managua 2006)”. Istmo. Revista virtual de estudios literarios y culturales centroamericanos 13(2006). <http://collaborations.denison.edu/istmo/n13/noticias/memoriam.html>. 7 julio 2009.

Arias, Arturo. "Literary Production and Political Crisis in Central America”. International Political Science Review 12/1 (1991): 15-28.

Aguirre, Erick. "Historia, nación y alteridad en dos novelas del Caribe centroamericano: Columpio al aire de Lizandro Chávez Alfaro y Calypso de Tatiana Lobo”. Historia y ficción en la novela centroamericana contemporánea. Werner Mackenbach, Rolando Sierra y Magda Zavala, eds. Tegucigalpa: Subirana, 2008. 81-90.

Bachmann, Pauline. "La negociación de identidades culturales/nacionales: Representaciones del Caribe en las novelas Limón Blues y Columpio al aire". Istmo. Revista virtual de estudios literarios y culturales centroamericanos 17 (2008). <http://collaborations.denison.edu/istmo/n17/proyectos/bachmann.html>. 15 agosto 2009.

Blandón, Erick. Vuelo de cuervos. Managua: Vanguardia, 1997.

Bourgois, Philippe. "Class, Ethnicity and the State among the Miskitu Amerindians of Northeastern Nicaragua”. Latin American Perspectives 8/2 (1981): 22-39.

Castro Jo, Carlos. "Raza, conciencia de color y militancia negra en la literatura nicaragüense”. Wani. Revista del Caribe Nicaragüense 33 (2003): 21-32.

Chávez Alfaro, Lizandro. Columpio al aire. Managua: UCA, 1999.

Cuadra, Pedro. La reincorporación de la Mosquitia. Estudio de interpretación histórica. León: Hospicio, 1964.

Cunningham Kain, Myrna. "El fraude del mestizaje: Anotaciones sobre el racismo en la Nicaragua multiétnica”. Wani. Revista del Caribe Nicaragüense 55 (2008): 6-16.

Delgado Aburto, Leonel, ed. "Lugar del letrado, lugar de la cultura, lugar del otro: Nuevas articulaciones de la novela nicaragüense durante los noventa”. Márgenes

Revista Iberoamericana, Vol. LXXIX, Núm. 242, Enero-Marzo 2013, $95-110$
ISSN 2154-4794 (Electrónico) 
recorridos: apuntes sobre procesos culturales y literatura nicaragüense del siglo XX. Managua: IHNCA/UCA, 2002. 53-93.

Duncan, Quince. “Corrientes literarias afrocentroamericanas”. Tensiones de la modernidad. Del modernismo al realismo. Valeria Grinberg Pla y Ricardo Roque Baldovinos, eds. Guatemala: F\&G, 2010. 513-29.

Dunbar Ortiz, Roxanne. "Indigenous Rights and Regional Autonomy in Revolutionary Nicaragua”. Latin American Perspectives 14/1 (1987): 43-66.

Fernández de Lizardi, Joaquín. El Periquillo Sarniento. 2ª ed. México: s.e., 1884.

Foucault, Michael. “OfOther Spaces: Utopias and Heterotopias”. Rethinking Architecture: A Reader in Cultural Theory. Neil Leach, ed. Londres: Routledge, 1997. 350-55. Freeland, Jane. A Special Place in History. The Atlantic Coast in the Nicaraguan Revolution. Londres: Nicaragua Solidarity Campaign, 1988.

Gordon, Edmund. Disparate Diasporas: Identity and Politics in an African Nicaraguan Community. Austin: U of Texas P, 1998.

Grinberg Pla, Valeria. "La novela histórica de las últimas décadas y las nuevas corrientes historiográficas”. Historia y ficción en la novela centroamericana contemporánea. Werner Mackenbach, Rolando Sierra y Magda Zavala, eds. Tegucigalpa: Subirana, 2008. 13-48.

Hale, Charles. Resistance and Contradiction: Miskitu Indians and the Nicaraguan State, 1894-1987. Stanford: Stanford UP, 1994.

Lefebvre, Henri. “The Production of Space”. Rethinking architecture: a reader in cultural Theory. Neil Leach, ed. Londres: Routledge, 1997. 139-46.

Mackenbach, Werner. "Representaciones del Caribe en la narrativa centroamericana contemporánea”. Istmo. Revista virtual de estudios literarios y culturales centroamericanos 5(2003). <http://collaborations.denison.edu/istmo/n05/articulos/ representaciones.html>. 4 abril 2009.

Die unbewohnte Utopie. Der nicaraguanische Roman der achtziger und neunziger Jahre. Frankfurt am Main: Vervuert, 2004.

Rodríguez Rosales, Isolda. "Nueva mirada a la 'otra historia' del caribe, en Columpio al aire (Novela de Lizandro Chávez Alfaro)”. Istmo. Revista virtual de estudios literarios y culturales centroamericanos 4 (2002). <http://collaborations.denison. edu/istmo/n04/proyectos/mirada.html>. 8 junio 2009.

Romero Vargas, Germán. Historia de la Costa Atlántica. Managua: CIDCA-UCA, 1996.

Sollis, Peter. "The Atlantic Coast of Nicaragua: Development and Autonomy”. Journal of Latin American Studies 21/3 (1989): 481-520.

Vilas, Carlos. Del colonialismo a la autonomía: modernización capitalista y revolución social en la Costa Atlántica. Managua: Nueva Nicaragua, 1990.

Wünderich, Volker. Sandino en la costa: de las Segovias al litoral atlántico. Managua: Nueva Nicaragua, 1989.

ISSN 0034-9631 (Impreso) 